\title{
Bottom-up synthesis of ultra-small molybdenum disulfide- polyvinylpyrrolidone nanosheets for imaging-guided tumor regression
}

\author{
Jiulong Zhao' ${ }^{1, *}$, Chunhua Zhou ${ }^{1,2, *}$, Mao Li, ${ }^{1,}$, Jialing $\mathrm{Li}^{1}$, Guixiang $\mathrm{Li}^{1}$, Dan Ma ${ }^{1}$, \\ Zhaoshen $\mathbf{L i}^{1}$ and Duowu Zou ${ }^{1}$ \\ ${ }^{1}$ Department of Gastroenterology, Changhai Hospital, Second Military Medical University, Shanghai 200433, China \\ ${ }^{2}$ Department of Gastroenterology, The Second Affiliated Hospital of Soochow University, Suzhou 215004, China \\ "These authors have contributed equally to this work
}

Correspondence to: Duowu Zou, email: zdw_pi@163.com

Keywords: molybdenum disulfide; ultra-small; bottom-up; cell nucleus; photothermal therapy

Received: June 27, $2017 \quad$ Accepted: August 27, $2017 \quad$ Published: November 08, 2017

Copyright: Zhao et al. This is an open-access article distributed under the terms of the Creative Commons Attribution License 3.0 (CC BY 3.0), which permits unrestricted use, distribution, and reproduction in any medium, provided the original author and source are credited.

\section{ABSTRACT}

The two-dimensional molybdenum disulfide $\left(\mathrm{MoS}_{2}\right)$ nanosheet has been extensively studied as a novel photothermal transducing agent. However, top-down exfoliation to produce MoS $_{2}$ nanosheets is inefficient, and MoS $_{2}$ nanosheet surface modification procedures are complex. Here, we report the synchronous synthesis and surface modification of 2D MoS ${ }_{2}$ nanosheets with a polyvinylpyrrolidone (PVP)assisted one-pot hydrothermal method. Due to the chelating-coordinating effect between the lone-pair electrons of the PVP carbonyl oxygen and the unoccupied 4d orbitals of molybdenum, the PVP chains could graft onto the surface of $\mathrm{MoS}_{2}$ and guide the growth of the nanosheets. The resultant MoS $_{2}-P V P$ nanosheets were ultrasmall (21.4 $\pm 4.4 \mathrm{~nm}$ ) and exhibited excellent colloidal stability. Moreover, the strong near-infrared absorption of the MoS $_{2}$-PVP nanosheets enabled sensitive photothermal conversion performance (with a mass extinction coefficient of $23.33 \mathrm{~L} \mathrm{~g}^{-1} \mathrm{~cm}^{-1}$ ) and in vitro/in vivo photoacoustic imaging. The $\mathrm{MoS}_{2}$-PVP nanosheets had excellent in vitro and in vivo compatibility and were used for highly efficient tumor photothermal therapy in xenograft tumor-bearing mice. The findings in this report will facilitate the rational design of stable colloidal 2D transition-metal dichalcogenides for effective photothermal cancer therapy.

\section{INTRODUCTION}

Nanomaterials have gained tremendous popularity in the field of biomedicine due to their fascinating physical/ chemical properties [1]. The successful exfoliation of graphene sheets from bulk graphite in 2004 by Novosolev, Geim and colleagues initiated the exploration of various kinds of two-dimensional (2D) nanomaterials [2, 3]. Unlike zero- and one-dimensional nanostructures, these novel 2D nanomaterials (including nanosheets, nanoplates and nanodisks) can be one atomic layer thick, which enables greatly compelling quantum size effects and unusual physical properties [4-8]. Due to these advantages, tremendous progress in 2D nanomaterials has been made in the sensor, catalysis, energy storage/conversion and biomedical fields [9-12]. As a typical member of the 2D nanomaterial family, $\mathrm{MoS}_{2}$ has been the focus of increasing research interest in the biomedical field [13-17]. Beyond the general properties of biomaterials such as biocompatibility, hemocompatibility and histocompatibility, another notable characteristic of $\mathrm{MoS}_{2}$ nanosheets is their strong near-infrared (NIR) absorbance, which enables superior photothermal transformation and photoacoustic imaging for tumor diagnosis and therapy $[16,17]$.

$\mathrm{MoS}_{2}$ has a hexagonal layer structure composed of Mo atoms sandwiched between two layers of $\mathrm{S}$ atoms [18, 
19]. Since bulk $\mathrm{MoS}_{2}$ is stacked layer-by-layer under a weak Van der Waals force, $\mathrm{MoS}_{2}$ nanosheets can be "topdown" exfoliated or peeled from the bulk form by means of intercalation reagents or external mechanical force [13, 16, 20-22]. In a pioneer study, Chou et al. synthesized $\mathrm{MoS}_{2}$ nanosheets by the top-down chemical exfoliation approach, and this $\mathrm{MoS}_{2}$ nanosheet category exhibited a marked photothermal performance improvement over graphene oxide and gold nanorods [13]. Liu et al. reported the possibility of using top-down chemically exfoliated PEGylated $\mathrm{MoS}_{2}$ nanosheets as a drug delivery system for synergistic photothermal therapy (PTT) and chemotherapy [16]. Recently, Zhao and co-workers proposed an "improved intercalation-exfoliation process" based on liquid-phase oleum exfoliation for top-down $\mathrm{MoS}_{2}$ production. The resultant $\mathrm{MoS}_{2}$ nanosheets decorated with chitosan could be used as chemotherapeutic drug nanocarriers for photothermally triggered drug delivery [22].

The top-down approach has been the most frequently studied method of producing $\mathrm{MoS}_{2}$ in the laboratory; however, the design of $2 \mathrm{D}$ nanomaterials by the topdown method, especially chemical exfoliation, has a series of drawbacks $[13,17]$. For instance, the product yield is low, the morphology is difficult to control, and on most occasions, complicated surface modifications are needed [23]. On these grounds, a method of obtaining a biocompatible nanoplatform using only a one-step reaction while simultaneously modifying the surface is desirable to promote the application of $\mathrm{MoS}_{2}$ in biomedicine. Shi and colleagues previously proposed a one-pot "bottom-up" solvothermal route for the successful synthesis and surface modification of $\mathrm{MoS}_{2}$ nanosheets through solvothermal treatment of an aqueous solution of ammonium tetrathiomolybdate $\left(\left(\mathrm{NH}_{4}\right)_{2} \mathrm{MoS}_{4}\right)$ and polyethylene glycol(PEG-400). This bottom-up strategy broke through the bottlenecks of top-down materials synthesis by allowing one-step morphology control and surface modification [17].

Polyvinylpyrrolidone (PVP) is a surfactant that not only controls the particle size, but also imparts colloidal stability to the yielded products [15]. In this study, we extended the one-pot approach to the synthesis of PVPdecorated $\mathrm{MoS}_{2}$ nanosheets by selecting ammonium tetrathiomolybdate as the precursor and PVP as the modifier. Due to the chelating-coordinating effect between the lone-pair electrons of the PVP carbonyl oxygen and the unoccupied $4 \mathrm{~d}$ orbitals of Mo, the PVP chains could graft onto the surface of $\mathrm{MoS}_{2}$ and guide the growth of the nanosheets during the hydrothermal process. The ultra-small $\mathrm{MoS}_{2}$-PVP nanosheets had strong colloidal stability, high in vitro and in vivo compatibility and excellent photothermal conversion performance, and were successfully prepared and used for highly efficient tumor PTT in a xenograft tumor-bearing mouse. Due to their NIR absorbance, these ultra-small $\mathrm{MoS}_{2}$ nanosheets were sensitive in vitro and in vivo photoacoustic imaging contrast agents. To our knowledge, this is the first study concerning the synthesis and morphology control of ultra-small $\mathrm{MoS}_{2}$ nanosheets and their use in tumor PTT therapy. This research highlights the possibility of surface modification based on the chelatingcoordinating effect between polymer chains and the unoccupied orbitals of transition metal atoms.

\section{RESULTS AND DISCUSSION}

The overall design concept and schematic hydrothermal treatment procedure for the synthesis of $\mathrm{MoS}_{2}-$ PVP nanosheets can be found in Figure 1A. The lone-pair electrons of the carbonyl oxygen of PVP could chemically react with the empty orbitals of Mo via the chelatingcoordinating effect. Due to this molecular-level force, the PVP chains could confine the growth of the nanosheet and guide the material extension along the polymer chains. On the other hand, this chelating-coordinating effect made it possible for the surface PVP to trap the nanomaterials. Without the addition of PVP, the size of the produced sheetlike $\mathrm{MoS}_{2}$ was about $50 \mathrm{~nm}$ (Supplementary Figure 1). Although atomic force microscopy is a powerful method to determine the thickness of nanosheets, it was unsuitable for the $\mathrm{MoS}_{2}$ nanosheets prepared by our "bottom-up" method because their morphology was crooked.

The Mw and concentration of PVP influenced the growth of the nanosheets (Supplementary Figures $2 \&$ 3). When the Mw of the added PVP was $360 \mathrm{kDa}$, the product retained a well-defined and uniform sheet-like shape, but the size dramatically decreased to $21.4 \pm 4.4 \mathrm{~nm}$ and the thickness was about $1 \mathrm{~nm}(0.9 \pm 0.2 \mathrm{~nm}$, Figure 1B). PVP with a Mw of $30 \mathrm{kDa}$ guided the growth of the $\mathrm{MoS}_{2}$ nanosheets; however, because the polymer chains were short, the weak constraining force was insufficient to support nanosheet growth, so impure-phase nanoparticles were formed (Supplementary Figure 2). We found that even smaller $\mathrm{MoS}_{2}$ nanosheets $(14.7 \pm 1.2 \mathrm{~nm})$ could be synthesized when the PVP concentration was doubled $(\mathrm{Mw}=360 \mathrm{kDa}, 10 \mathrm{mg} / \mathrm{mL}$, Supplementary Figure 3).

These results clearly indicated that the size and morphology of the nanosheets could be altered through tuning of the PVP Mw and concentration. Although a detailed mechanism has not been clearly established yet, it seems likely that the PVP concentration and the length of the polymer chain influence the chelating-coordinating force and thus induce these size and morphology changes. Considering the well-defined 2D particulate morphology and colloidal stability (discussed below) of PVP with a Mw of $360 \mathrm{kDa}$, we selected it as the modifier for the one-pot synthesis and surface modification of $\mathrm{MoS}_{2}$ nanosheets.

XPS and XRD were performed to analyze the chemical composition and structure of the nanosheets (Figure 2A-2C). Characteristic peaks of $\mathrm{MoS}_{2}$ located at $229.2 \mathrm{eV}$ (Mo 3d 5/2) and $230.8 \mathrm{eV}$ (Mo 3d 3/2) (corresponding to $\mathrm{Mo}^{4+}$ ), as well as at $227.6 \mathrm{eV}$ (S 2s), $167.4 \mathrm{eV}$ (S 2p 1/2) and $160.1 \mathrm{eV}$ (S 2p 3/2) (corresponding to $\mathrm{S}^{2-}$ ) were detected in the XPS spectra 
(Figure 2A, 2B). With the exception of C, O and Si, which originated from the surface-modified PVP and the sample scaffold for EDS analysis, no other element was observed in the EDS spectrum (Supplementary Figure 4). Moreover, the XRD pattern matched the crystalline structure of $\mathrm{MoS}_{2}$ well (Figure 2C).

Fourier transform infrared spectroscopy was carried out to determine the success of the PVP grafting during the hydrothermal process. A remarkable peak intensity increase was found at $1650 \mathrm{~cm}^{-1}$, belonging to the stretching vibration of the carbonyl groups of PVP (Figure 2D). Moreover, two peaks were clearly detected at $2955 \mathrm{~cm}^{-1}$ and $1434 \mathrm{~cm}^{-1}$, which could be ascribed to the stretching and bending vibrations of $\mathrm{C}-\mathrm{H}$ bonds, indicating the existence of PVP chains on the nanosheet surface. These characterization data suggested that the chemical essence of the as-prepared nanosheet was $\mathrm{MoS}_{2}$, and that the PVP introduced during the synthesis was successfully anchored onto the product surface (noted as $\mathrm{MoS}_{2}-\mathrm{PVP}$ ).

The surface-decorating PVP chains guaranteed the excellent colloidal stability of the $\mathrm{MoS}_{2}$-PVP nanosheets in different surroundings. They could be well-dispersed in water, saline, RPMI 1640 cell culture medium and FBS to form stable dispersions (Figure 3G \& Supplementary Figure 5) with the typical Tyndall effect (Figure 3D-3F).
The DLS diameters of $\mathrm{MoS}_{2}$-PVP nanosheets in the above dispersions exhibited negligible fluctuations within $72 \mathrm{~h}$ standing at room temperature (Figure $3 \mathrm{~A}-3 \mathrm{C} \& 3 \mathrm{H}$ ). It is worth noting that the DLS diameter was larger than the TEM size (Figure 1B-1C), which may have been due to the formation of a hydration shell around the nanosheets after the anchoring of the surface PVP molecules. Apparently, the surface PVP modification enhanced the colloidal stability much more effectively than PEG-400, which only maintained stability under physiological conditions for $24 \mathrm{~h}$ [17].

\section{In vitro photothermal performance}

To explore the cancer PTT treatment potential of the as-prepared $\mathrm{MoS}_{2}$-PVP nanosheets, we next focused our research efforts on their light-absorption features. Similar to top-down exfoliated 2D $\mathrm{MoS}_{2}$ nanosheets [13], $\mathrm{MoS}_{2}$ PVP nanosheets exhibited broad absorption in the NIR region (Figure 3G, the insert contains a zoomed-in picture of the light absorption at 750-850 nm). The NIR absorption of nanosheets correlates closely with their size; thus, the ultra-small $\mathrm{MoS}_{2}$-PVP nanosheets could absorb more from the NIR laser than large $\mathrm{MoS}_{2}$ nanosheets $(50 \mathrm{~nm})$ at the same Mo concentration (Figure 3I). The mass extinction
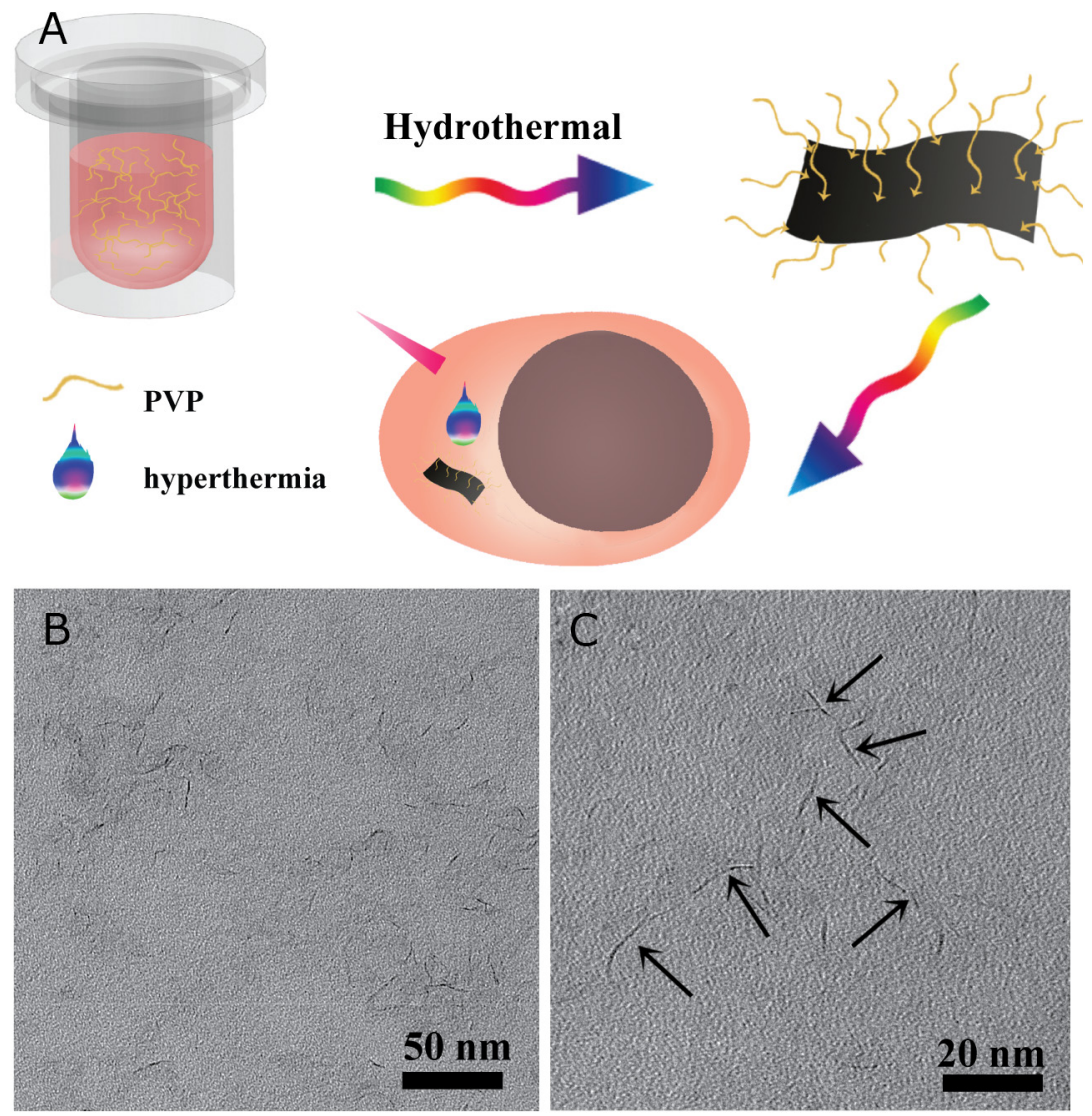

Figure 1: (A) Schematic illustration of the solvothermal synthesis procedure of $\mathrm{MoS}_{2}$-PVP nanosheets and PTT; (B) TEM image of MoS PVP nanosheets; (C) enlarged TEM image of (B). 
coefficient of the $\mathrm{MoS}_{2}$-PVP nanosheets at $800 \mathrm{~nm}$ was calculated to be $23.33 \mathrm{~L} \mathrm{~g}^{-1} \mathrm{~cm}^{-1}$, which was much higher than that of graphene oxide $\left(3.6 \mathrm{~L} \mathrm{~g} \mathrm{~g}^{-1} \mathrm{~cm}^{-1}\right)$ and similar to those of reduced graphene oxide $\left(24.6 \mathrm{~L} \mathrm{~g} \mathrm{~g}^{-1} \mathrm{~cm}^{-1}\right)$ and chemically exfoliated $\mathrm{MoS}_{2}$-PEG nanosheets [16].

The obvious NIR laser absorbance, along with the excellent hydrophilicity and dispersity in different physiological media, encouraged us to pursue the potential of $\mathrm{MoS}_{2}$-PVP nanosheets as photothermal agents. For this purpose, we exposed a series of $\mathrm{MoS}_{2}$-PVP nanosheet dispersions to the NIR laser at a pre-determined power density to explore the correlation of the photothermal performance with the concentration, irradiation time and power density. The photothermal conversion capacity of the $\mathrm{MoS}_{2}$-PVP nanosheets depended on the nanosheet concentration and power density. The temperature increases $(\Delta \mathrm{T})$ were $8.3{ }^{\circ} \mathrm{C}, 19.5^{\circ} \mathrm{C}$ and $29.6{ }^{\circ} \mathrm{C}$ when the Mo concentrations were 25, 50 and $100 \mathrm{ppm}$, respectively, at a low power density of $0.6 \mathrm{~W} / \mathrm{cm}^{2}$ (Figure 4A, 4B). Similarly, the $\Delta \mathrm{T}$ of the $\mathrm{MoS}_{2}$-PVP nanosheet solution increased with the NIR laser power density (Figure 4C, 4D), being $8.9^{\circ} \mathrm{C}, 19.7{ }^{\circ} \mathrm{C}$ and $34.7{ }^{\circ} \mathrm{C}$ when the laser power densities were $0.2 \mathrm{~W} / \mathrm{cm}^{2}, 0.4 \mathrm{~W} / \mathrm{cm}^{2}$ and $0.6 \mathrm{~W} /$ $\mathrm{cm}^{2}$, respectively. Unlike the $\mathrm{MoS}_{2}-\mathrm{PVP}$ nanosheets, pure water exhibited no detectable temperature variation $\left(\Delta \mathrm{T}=2.1{ }^{\circ} \mathrm{C}\right)$, even at a power density of $1.0 \mathrm{~W} / \mathrm{cm}^{2}$ (Supplementary Figure 6).
The influence of the surface PVP molecules on the photothermal performance was also investigated. As $\mathrm{MoS}_{2}$-PVP nanosheets exhibited stronger laser absorbance than $\mathrm{MoS}_{2}$ nanosheets without surface modification (Figure 3I), they also displayed enhanced photothermal performance, with $\Delta \mathrm{T}$ increases of about 5.3 and $7.2^{\circ} \mathrm{C}$ at power densities of $0.4 \mathrm{~W} / \mathrm{cm}^{2}$ and $1.0 \mathrm{~W} / \mathrm{cm}^{2}$, respectively (Figure 4E, F). In addition to excellent photothermal performance, the $\mathrm{MoS}_{2}$-PVP nanosheets demonstrated desirable photothermal stability. In cycling temperaturechange monitoring experiments, the maximum temperature change during five cycles of irradiation displayed no appreciable variation (Supplementary Figure 7, $50 \mathrm{ppm}, 0.6 \mathrm{~W} / \mathrm{cm}^{2}$ ), implying that five cycles of NIR laser irradiation did not significantly influence the photothermal stability of the $\mathrm{MoS}_{2}$-PVP nanosheets. The unique NIR absorbance, excellent photothermal performance and great stability of the $\mathrm{MoS}_{2}-\mathrm{PVP}$ nanosheets highlight their potential as stable and durable photothermal agents for tumor PTT.

\section{Cellular uptake of $\mathrm{MoS}_{2}$ nanosheets}

The intracellular uptake of $\mathrm{MoS}_{2}$-PVP nanosheets could substantially influence their effectiveness for in vitro cancer cell PTT. Tunable cellular uptake is a prerequisite for effective PTT. A large number of $\mathrm{MoS}_{2}-$
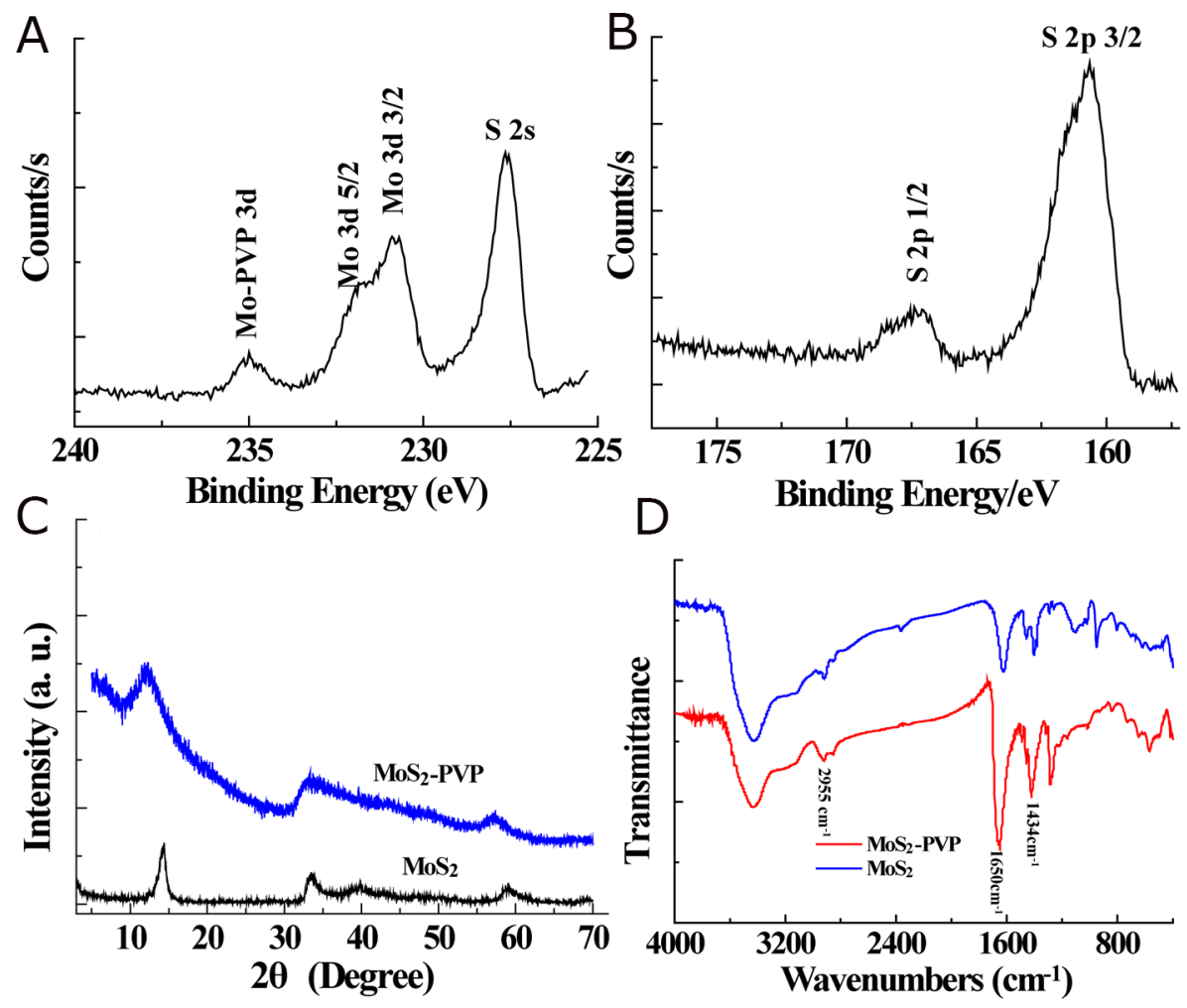

Figure 2: (A) XPS spectrum of Mo 3d and S 2s orbits; (B) XPS spectrum of S 2p orbits. (C) XRD patterns and (D) FTIR spectra of pure $\mathrm{MoS}_{2}$ and $\mathrm{MoS}_{2}-\mathrm{PVPnanosheets.}$ 
PVP nanosheets that were trapped by small vesicles in the cytoplasm were observed by Bio-TEM (Supplementary Figure 8A, indicated by the arrows), clearly indicating that the $\mathrm{MoS}_{2}$ nanosheets were taken up by cells via endocytosis (Supplementary Figure 8B). Further quantitative evaluation by ICP-OES demonstrated that the specific cellular uptake amount was $\sim 80 \mu \mathrm{g} /$ well. Similar to surface PEG grafting [25], surface PVP-chain anchoring was anticipated to facilitate nutritional absorption from the cell culture medium and promote the cellular uptake of $\mathrm{MoS}_{2}$-PVP nanosheets. We expected that this material uptake by cancer cells, especially the cell nuclei, would greatly enhance the PTT performance of the $\mathrm{MoS}_{2}-\mathrm{PVP}$ nanosheets by enabling them to target and destroy the nucleus passively via hyperthermia under NIR irradiation.

\section{In vitro cytocompatibility and PTT}

In order to be safely applied in biomedicine, $\mathrm{MoS}_{2}$ PVP nanosheets should not cause any cellular damage or toxicity. Therefore, we next evaluated the in vitro cytocompatibility of $\mathrm{MoS}_{2}$-PVP nanosheets using the standard CCK-8 assay. The $\mathrm{MoS}_{2}-\mathrm{PVP}$ nanosheets were minimally toxic to both HT29 and L929 cells. After these cells were incubated with $\mathrm{MoS}_{2}$-PVP nanosheets for 24 $\mathrm{h}$, their viabilities were negligibly reduced, even at a high nanosheet concentration of $200 \mu \mathrm{g} / \mathrm{mL}$ (L929: $\sim 87 \%$ [Supplementary Figure 9] and HT29: 100\% [Figure 5A]). In addition to the CCK-8 assay, trypan blue staining (which stains apoptotic/dead cells blue) was performed as further proof of the negligible cytotoxicity of the $\mathrm{MoS}_{2}-$
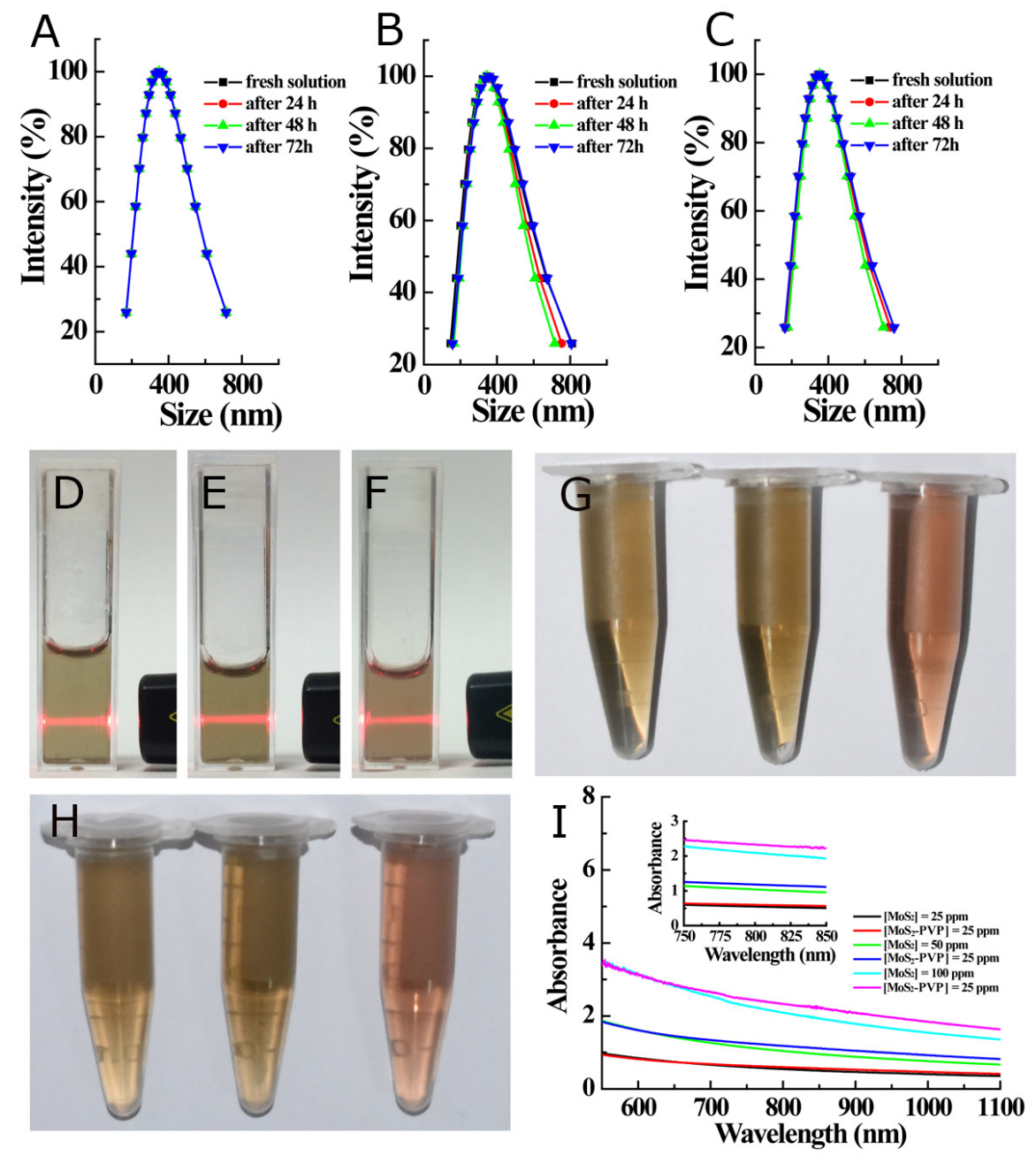

Figure 3: (A-C) Time-dependent DLS of $\mathrm{MoS}_{2}-\mathrm{PVP}$ nanosheets in different media: (A) distilled water, (B) saline, and (C) RPMI 1640 cell culture medium; (D-F) photographic images of typical Tyndall light scattering of $\mathrm{MoS}_{2}-\mathrm{PVP}$ in different media: (D) distilled water, (E) saline, (F) RPMI-1640 cell culture medium; (G) photographic image of fresh $\mathrm{MoS}_{2}-\mathrm{PVP}$ aqueous solutions (left: distilled water, middle: saline, right: RPMI 1640 medium); (H) photographic images of MoS2-PVP aqueous solutions (left: distilled water, middle: saline, and right: RPMI 1640 medium) after three days standing; (I) UV-Vis-NIR spectra of MoS2 and MoS2-PVP aqueous solutions at different concentrations; the insert contains a zoomed-in picture of the light absorption at 750-850 $\mathrm{nm}$. 
PVP nanosheets. Similar to the results in saline-treated HT29 (Figure 5C) and L929 cells (Supplementary Figure 9B), the morphological integrity of HT29 and L929 cells was not destroyed after the cells were incubated with $\mathrm{MoS}_{2}$-PVP nanosheets at a high concentration of $200 \mu \mathrm{g} / \mathrm{mL}$ (Figure 5D and Supplementary Figure 9C), confirming that the cytotoxicity of $\mathrm{MoS}_{2}$-PVP nanosheets was negligible at the experimental dosage $(0-200 \mu \mathrm{g} / \mathrm{mL})$.

After demonstrating the excellent NIR-absorbing capacity and cytocompatibility of the $\mathrm{MoS}_{2}$-PVP nanosheets, we then studied their effectiveness for in vitro cancer cell photothermal ablation. When HT29 cells were incubated with $\mathrm{MoS}_{2}$-PVP nanosheets and irradiated with the NIR laser, their cellular viability decreased concentration-dependently (Figure 5B, bars 1-3). When incubated with $\mathrm{MoS}_{2}-\mathrm{PVP}$ nanosheets at a concentration of $200 \mathrm{ppm}$ for $6 \mathrm{~h}$, the majority of HT29 cells were killed by NIR-induced hyperthermia, such that their viability was reduced to $\sim 11 \%$ (Figure $5 \mathrm{~B}$, bar 1). When the nanosheet concentrations were reduced to 100 or $50 \mathrm{ppm}$, the cellular viability levels were $29.8 \pm 5.9 \%$ or $58.0 \pm 6.1 \%$, respectively (Figure $5 \mathrm{~B}$, bars 2 and 3 ). The apoptosis induced by hyperthermia was so swift that $40 \%$ of the cells died within $1 \mathrm{~min}(200 \mu \mathrm{g} / \mathrm{mL}$, cell viability of 60.2 $\pm 3.1 \%$, bar 4 ).

The in vitro cancer cell photothermal ablation was further evaluated with trypan blue staining. Consistent with the CCK-8 results, a large portion of the $\mathrm{MoS}_{2}-\mathrm{PVP}$ $(200 \mu \mathrm{g} / \mathrm{mL}$ )-treated HT29 cells were stained blue (Figure 5D) after irradiation with the laser for $1 \mathrm{~min}$, while after 5 min of irradiation, almost all of the HT29 cells were stained blue (Figure 5F). These results suggested that the $\mathrm{MoS}_{2}$-PVP nanosheets efficiently converted NIR light into thermal energy and significantly suppressed in vitro cell proliferation by inducing hyperthermia.

\section{In vivo compatibility of $\mathrm{MoS}_{2}$ nanosheets}

The in vitro hemocompatibility of the $\mathrm{MoS}_{2}$-PVP nanosheets toward mRBCs was evaluated by hemolysis, coagulation, serum biochemistry and routine blood testing [26]. The hemolytic assay was not applicable because the ultra-small $\mathrm{MoS}_{2}$-PVP nanosheets (which would
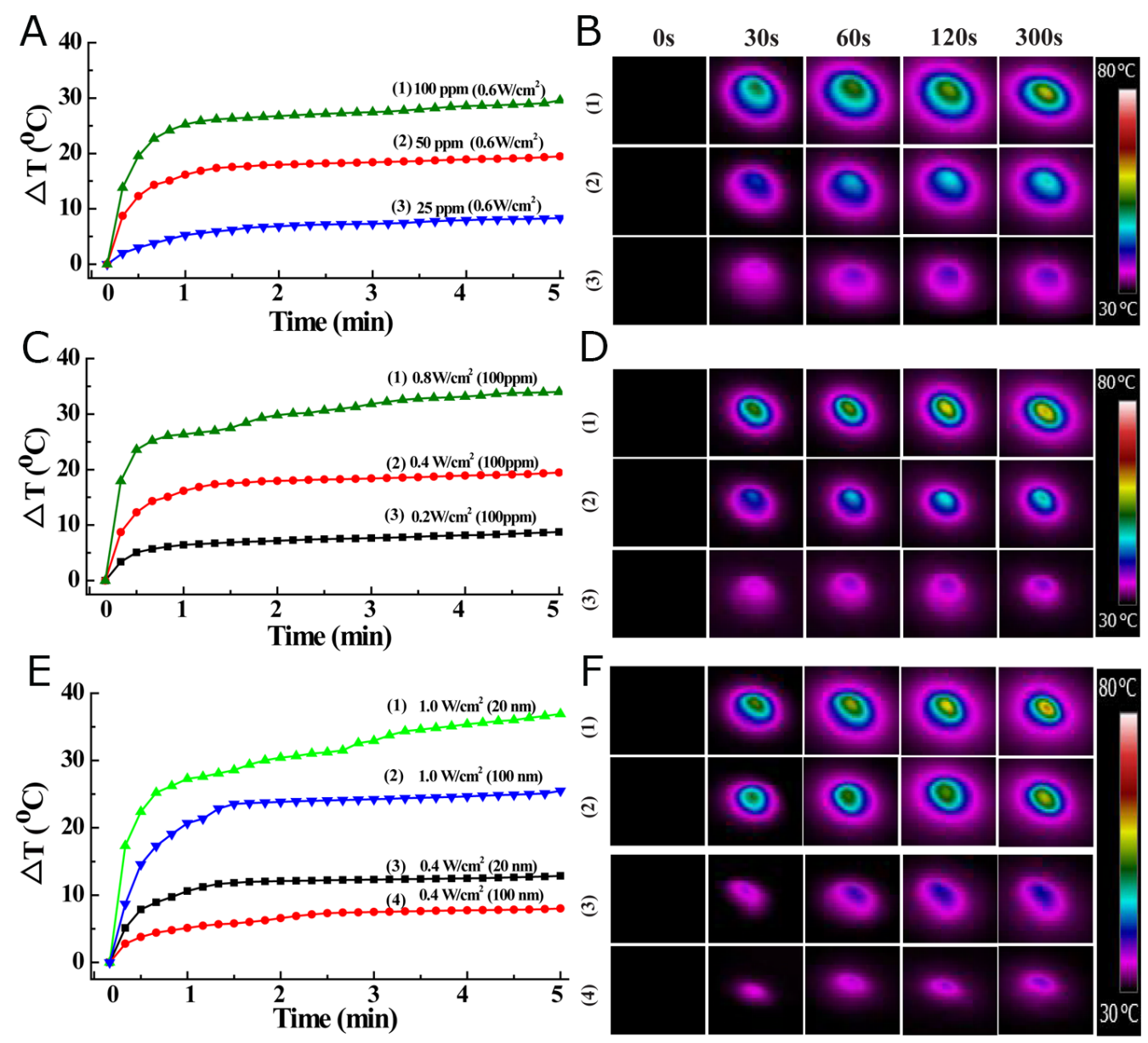

Figure 4: Temperature-change profiles of $\mathrm{MoS}_{2}-\mathrm{PVP}$ aqueous dispersions as a function of (A) $\mathrm{MoS}_{2}-\mathrm{PVP}$ concentration (power density: $\left.0.6 \mathrm{~W} / \mathrm{cm}^{2}\right),(\mathbf{C})$ power density $\left(\mathrm{MoS}_{2}\right.$ concentration: $\left.100 \mathrm{ppm}\right)$, and $(\mathbf{E})$ size (power density: 0.4 or $\left.1.0 \mathrm{~W} / \mathrm{cm}^{2}\right) ;(\mathbf{B}, \mathbf{D}, \mathbf{F})$ thermal images of $\mathrm{MoS}_{2}$-PVP aqueous solutions, corresponding to panels (A, C, E). 
have significantly influenced the light absorption) were difficult to separate from the $\mathrm{mRBC}$ dispersion, even at a high centrifugal speed of $12000 \mathrm{rpm}$. Therefore, after the mRBCs were incubated with $\mathrm{MoS}_{2}$-PVP nanosheets (200 $\mu \mathrm{g} / \mathrm{mL}$ ) for $2 \mathrm{~h}$, the cellular morphology was observed by Wright's staining method. The results (Supplementary Figure 10) clearly indicated that the structural integrity of the mRBCs was well-maintained after the cells were treated with $\mathrm{MoS}_{2}-\mathrm{PVP}$ nanosheets.

When KM mice were I.V. injected with $\mathrm{MoS}_{2}-\mathrm{PVP}$ nanosheets, coagulation functional assessment at days 1 and 28 revealed that the plasma coagulation indexes (APTT, FDP, FIB, PT and TT) remained in the same range as the control values (from saline-treated plasma) (Supplementary Figure 11), indicating that the $\mathrm{MoS}_{2}-\mathrm{PVP}$ nanosheets did not cause the coagulation. To assess the hemocompatibility further, we performed blood biochemistry and routine blood tests on days 1, 14 and 28 after I.V. injection of $\mathrm{MoS}_{2}-$ PVP nanosheets. No significant physiological differences in various routine blood indexes were found between the experimental and control mice, further confirming the favorable hemocompatibility of $\mathrm{MoS}_{2}$-PVP nanosheets at the experimental dosage (Supplementary Figure 12).

To demonstrate the in vivo safety of the $\mathrm{MoS}_{2}$ PVP nanosheets, we then monitored the body weights, $\mathrm{MoS}_{2}$-PVP nanosheet biodistribution patterns and tissue lesions of KM mice (Figure 6) after $\mathrm{MoS}_{2}-\mathrm{PVP}$ nanosheet administration. KM mice in both the control and treatment groups presented natural body weight increases and exhibited no obvious weight variation over the feeding time (Figure 6A). The amount of Mo in major organs (heart, liver, spleen, lung and kidney) after material administration was determined in KM mice sacrificed on days 1, 7, 14 and 28. High levels of the I.V.-injected materials were observed in the liver and spleen on day 1, indicating their accumulation in the reticuloendothelial system within the first $24 \mathrm{~h}$ [27]. Fortunately, the Mo levels in all organs decreased with time, and were quite low after 28 days, suggesting that the nanosheets were excreted from these organs (Figure $6 \mathrm{~B})$. The in vivo metabolism of the as-synthesized $\mathrm{MoS}_{2}-$ PVP nanosheets was similar to that previously reported for $\mathrm{MoS}_{2}-\mathrm{PEG}$ nanosheets [17], possibly indicating that
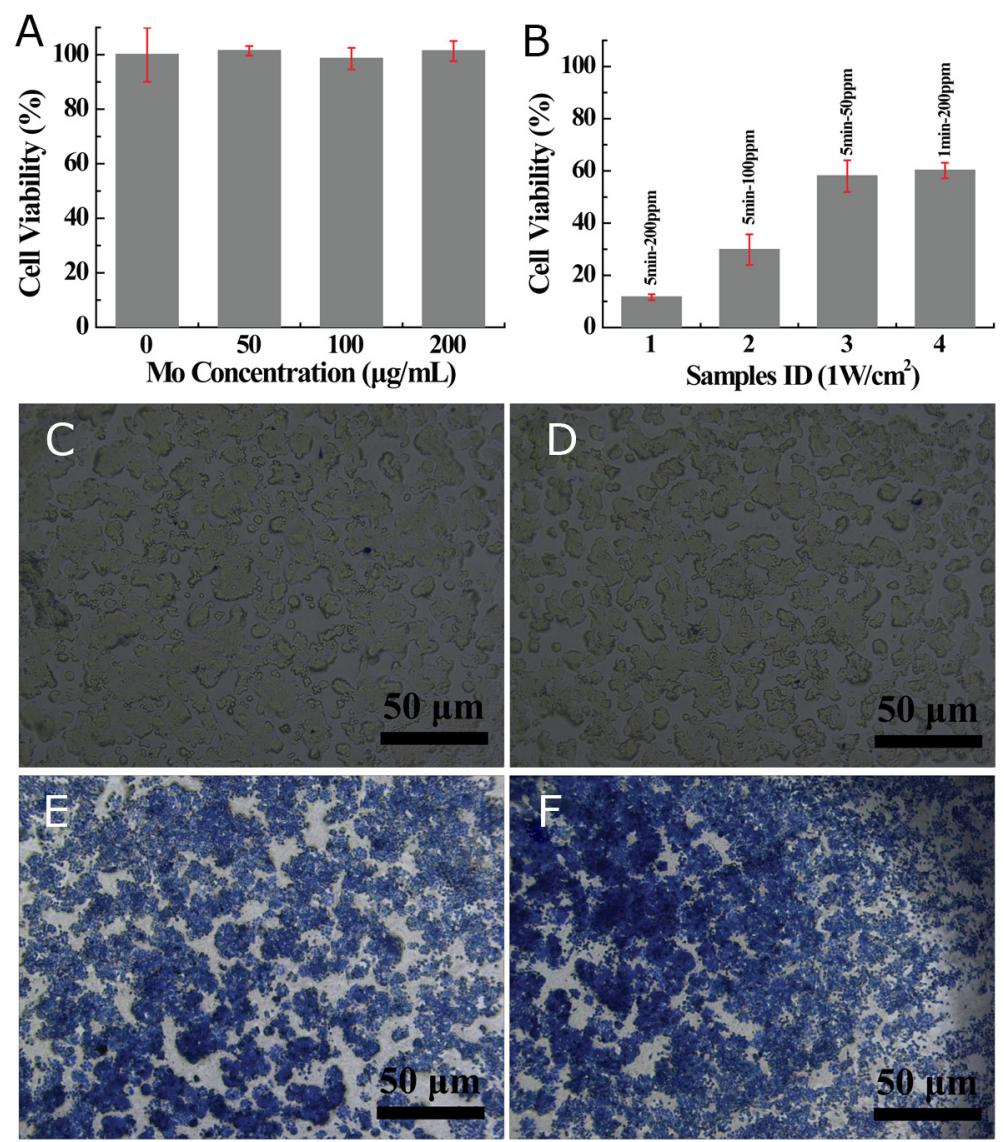

Figure 5: (A) Viability of HT29 cells incubated with different concentrations of $\mathrm{MoS}_{2}$-PVP nanosheets for 24 h; (B) in vitro PTT performance (irradiation time: 1 min or 5 min); (C-F) phase-contrast images of trypan blue-stained HT29 cell morphology: (C) HT29 cells treated with saline (control), (D) HT29 cells treated with $\mathrm{MoS}_{2}-\mathrm{PVP}$ nanosheets (concentration: $200 \mu \mathrm{g} / \mathrm{mL}$ ); (E, F) Cells treated with $\mathrm{MoS}_{2}-\mathrm{PVP}$ nanosheets at a concentration of $200 \mu \mathrm{g} / \mathrm{mL}$ and NIR irradiation for $1 \mathrm{~min}$ and $5 \mathrm{~min}$, respectively. 
the surface-decorating PVP macromolecules improved the blood circulation duration of the $\mathrm{MoS}_{2}$ nanosheets. It was difficult to determine the biodistribution of the pure $\mathrm{MoS}_{2}$ nanosheets, due to their poor colloidal stability.

To investigate whether the organ accumulation of the $\mathrm{MoS}_{2}$-PVP nanosheets would exert any adverse effects, we observed the tissue lesions of these organs with $\mathrm{H} \& \mathrm{E}$ staining. After $\mathrm{MoS}_{2}$ nanosheet administration and subsequent four-week feeding, no signs of acute or chronic pathological toxicity or adverse effects were observed in the control or treatment groups (Figure 6C). In general, the surface PVP-decorated $\mathrm{MoS}_{2}$ nanosheets exhibited excellent in vivo hemo/histocompatibility, and demonstrated promising potential as nano-agents for the PTT treatment of cancer.

\section{In vitro and in vivo photoacoustic imaging}

An ideal nanoscale NIR laser-absorber for photoacoustic imaging not only would have a sufficiently high extinction coefficient in the NIR region, but also would exert NIR irradiation-induced photoacoustic effects [28-30]. Therefore, $\mathrm{MoS}_{2}$-PVP nanosheets, which have outstanding NIR laser absorbance, should also have great potential as photoacoustic imaging contrast agents. To verify this hypothesis, we dropped different concentrations of $\mathrm{MoS}_{2}$-PVP nanosheets into small holes in a home-made agar plate, and scanned them to record their photoacoustic effects under NIR irradiation (680-970 nm). Figure 7A presents the photoacoustic signal intensities of $\mathrm{MoS}_{2}-\mathrm{PVP}$ nanosheet aqueous dispersions at different concentrations. The photoacoustic effect increased with the material concentration, as evidenced by the gradual deepening in brightness with increasing Mo concentrations (25 to 100 ppm). Moreover, the contrast could be clearly visualized even at a low Mo concentration of 25 ppm (Figure 7B).

This superior in vitro photoacoustic imaging capacity motivated us to assess the in vivo tumor imaging performance of the $\mathrm{MoS}_{2}$-PVP nanosheets in tumor-bearing $\mathrm{Balb} / \mathrm{c}$ nude mice. NIR lasers with wavelengths of $808 \mathrm{~nm}$ and $980 \mathrm{~nm}$ are two frequently used laser sources in tumor PTT. Since the absorbance of $\mathrm{WS}_{2}-\mathrm{PVP}$ nanosheets was higher at $808 \mathrm{~nm}$ than at $980 \mathrm{~nm}$, we chose $808 \mathrm{~nm}$ as the laser wavelength for quantitative photoacoustic imaging [8]. At a wavelength of $808 \mathrm{~nm}$, the photoacoustic signal intensity increased dramatically in HT29-xenografted tumors, regardless of whether I.T. or I.V. material injection was performed (Figure 7E-7G), confirming the possibility of using ultra-small $\mathrm{MoS}_{2}$-PVP nanosheets as qualified photoacoustic contrast agents in vivo.

\section{In vivo PTT performance of $\mathrm{MoS}_{2}-\mathrm{PVP}$ nanosheets}

Given the biocompatibility, tumor imaging capacity and in vitro tumor PTT efficiency of $\mathrm{MoS}_{2}-\mathrm{PVP}$

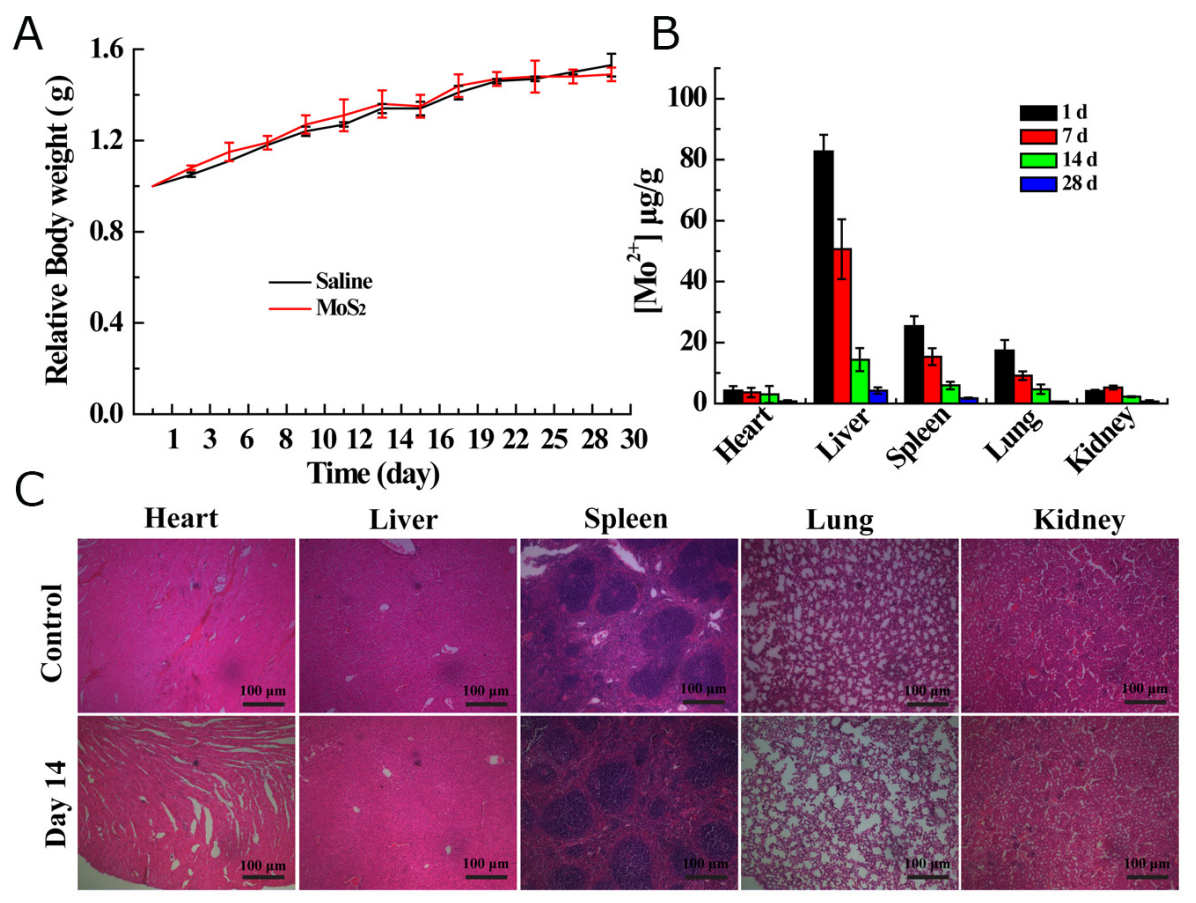

Figure 6: (A) Body weight changes of KM mice I. V. injected with saline or MoS - PVP nanosheets; (B) biodistribution of Mo in the heart, liver, spleen, lung and kidney at 1, 7, 14 and 28 days after I.V. injection with MoS $-P V P$ nanosheets (mean \pm standard deviation, $n=$ 3). (C) H\&E staining images of hearts, livers, spleens, lungs and kidneys from KM mice on day 14 after treatment with saline (control) or $\mathrm{MoS}_{2}$-PVP nanosheets (magnification: $100 \times$ ). 
nanosheets, we then carried out animal experiments to determine their in vivo tumor PTT effectiveness. Tumorbearing Balb/c nude mice were randomly divided into three groups, to be either I.V. injected with saline (control), I.V. injected with $\mathrm{MoS}_{2}$-PVP nanosheets, or I.T. injected with $\mathrm{MoS}_{2}$-PVP nanosheets. Then, the mice in the control and I.T.-injected groups were immediately exposed to the
NIR laser for $5 \mathrm{~min}$, while the mice in the I.V. material injection group received the 5-min laser irradiation $12 \mathrm{~h}$ after the injection, to allow the $\mathrm{MoS}_{2}$-PVP nanosheets to permeate the tumor tissue thoroughly.

Due to the apparent tumor retention of the I.T.injected materials, swift tumor temperature increases of about $18.6{ }^{\circ} \mathrm{C}$ and $23.5{ }^{\circ} \mathrm{C}$ were detected after 100 and
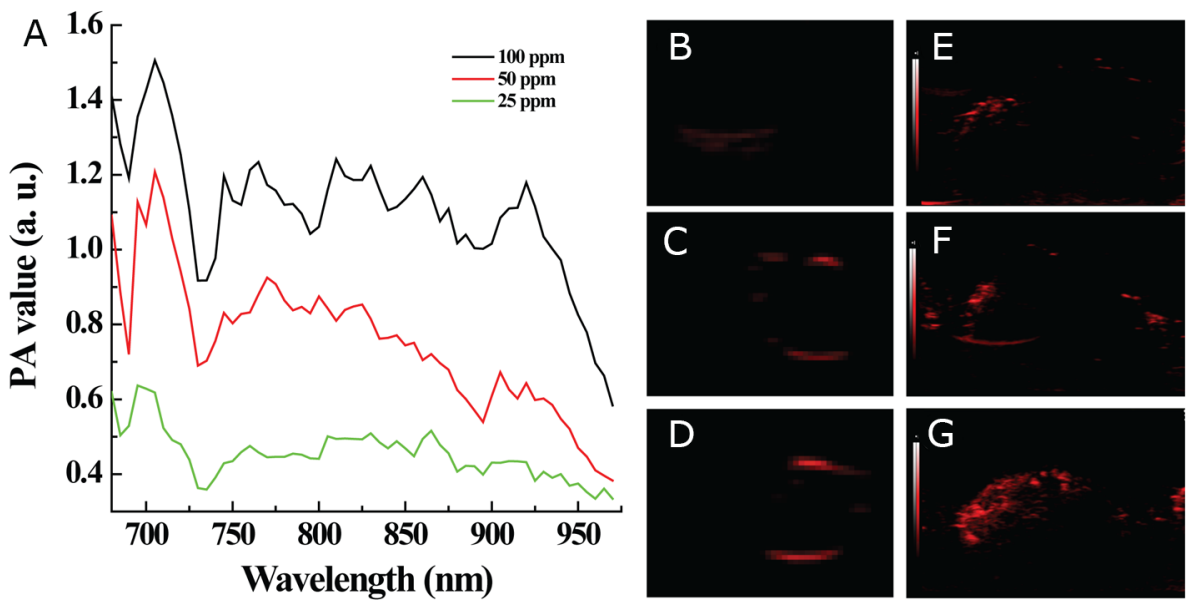

Figure 7: In vitro and in vivo photoacoustic imaging. (A) In vitro photoacoustic (PA) values versus $\mathrm{MoS}_{2}-\mathrm{PVP}$ nanosheet concentrations within the laser wavelength of 690-970 nm; (B-D) photoacoustic images at $\mathrm{MoS}_{2}$ concentrations of 25, 50 and 100 ppm, respectively, under NIR irradiation $(808 \mathrm{~nm})$; (E-G) in vivo photoacoustic images of tumors obtained from (E) a control mouse, (F) a mouse I.V. injected with $\mathrm{MoS}_{2}-\mathrm{PVP}$ nanosheets and (G) a mouse I.T. injected with $\mathrm{MoS}_{2}-\mathrm{PVP}$ nanosheets, under NIR irradiation (808 nm).
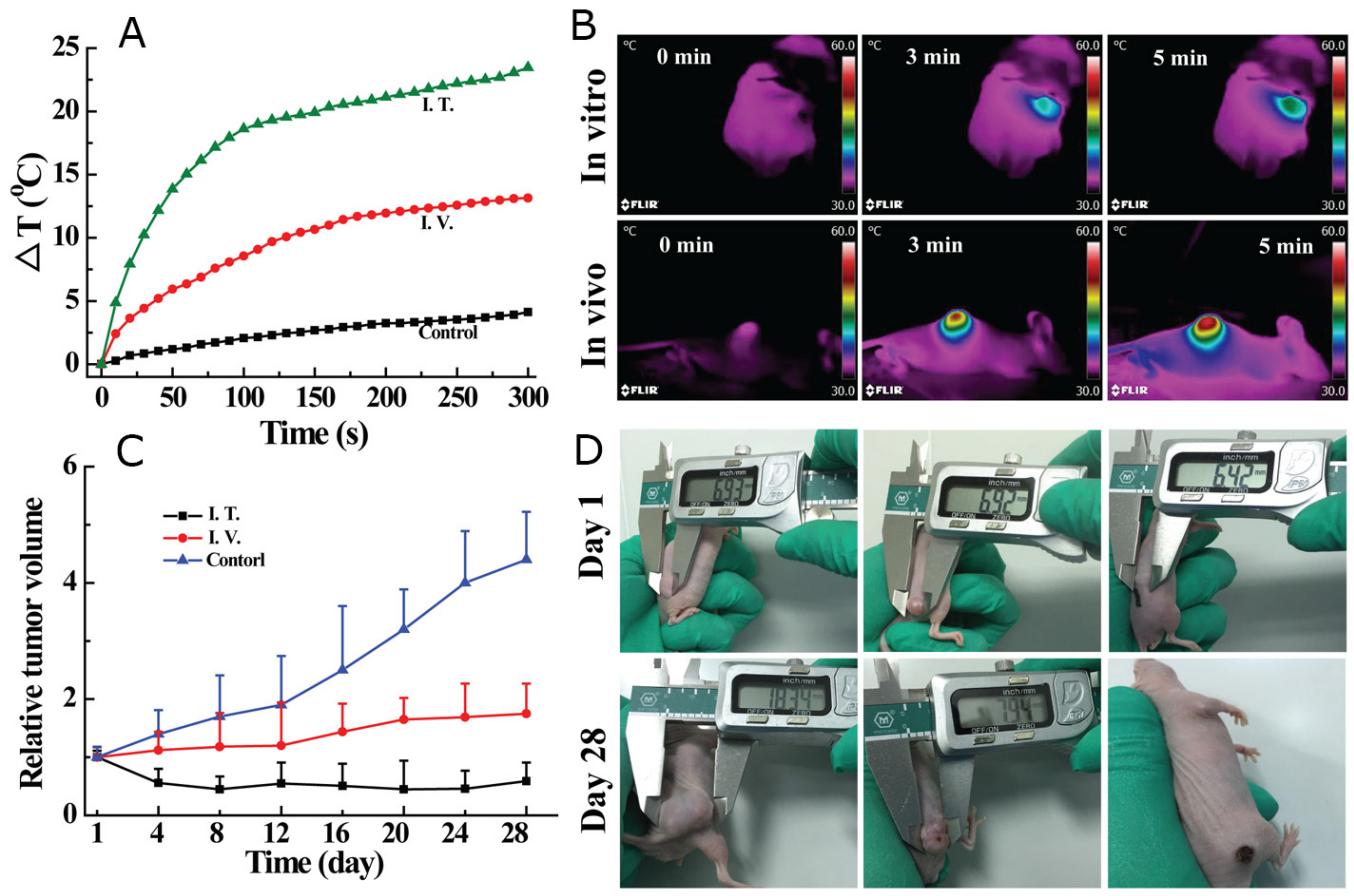

Figure 8: (A) Tumor temperature changes under NIR laser irradiation at a power density of $0.6 \mathrm{~W} / \mathrm{cm}^{2}$; (B) thermal images of mice before and after continuous irradiation with a NIR laser $\left(0.8 \mathrm{~W} / \mathrm{cm}^{2}\right)$ at different time points; (C) tumor volume changes of mice after different treatments as indicated; (D) digital photos of HT29 tumor-bearing mice on day 1 and day 28 after different treatments. Mice were I.V. injected with $100 \mu \mathrm{L}$ saline without $\mathrm{MoS}_{2}$-PVP nanosheets (control, left), or I.V. (center) or I.T. (right) injected with MoS 2 -PVP nanosheets. 
$300 \mathrm{~s}$ of laser irradiation, respectively (Figure 8A). The temperature increases were less remarkable for mice that were I.V. injected with $\mathrm{MoS}_{2}-\mathrm{PVP}$ nanosheets; moderate temperature increases of about $8.6^{\circ} \mathrm{C}$ and 13.2 ${ }^{\circ} \mathrm{C}$ were found during 100 and $300 \mathrm{~s}$ of laser irradiation, respectively (Figure $8 \mathrm{~A}$ ). The $\Delta \mathrm{T}$ distinction between the two groups was mainly due to differences in nanomaterial accumulation within the tumors; only a small portion of the nanosheets accumulated in the tumor sites of the I.V.-injected mice through the enhanced permeability retention effect. In sharp contrast, no obvious temperature fluctuation was observed in the control group; the temperature increased by only $5.6^{\circ} \mathrm{C}$, even after $300 \mathrm{~s}$ of laser irradiation (Figure 8A and Supplementary Figure 13).

After the tumor temperature was recorded, the mice were allowed to continue feeding so that the tumor volume could be measured over time. The tumor suppression effectiveness correlated positively with the temperature change, such that the tumor growth of I.T.-injected mice was totally inhibited (Figure $8 \mathrm{C}$ ), and all six mice in the group remained healthy with no tumor recurrence during the entire feeding duration. It is particularly noteworthy that although the photothermal efficiency was not as obvious in the I.V.-injected group as it was in the I.T.-injected group, I.V. material injection still efficiently suppressed tumor growth. Tumor growth was significantly retarded in I.V. materialadministered mice ( $p<0.05$, Figure $8 \mathrm{C}$ ), with the tumor expanding to about 1.75 times its original volume after 28 days. On the other hand, uncontrolled tumor growth was observed in the control group (treated with saline + laser), such that the final tumor volumes were approximately 4.4 times larger than the initial volumes, and the occasional mouse death occurred during four weeks of feeding.

In addition to the tumor volume and survival monitoring, pathological examination by immunohistochemical staining (CD31, KI67 and TUNEL) was also performed to assess the in vivo tumor PTT outcomes. To determine the microvessel density, a reflection of tumor angiogenesis, we detected CD31-positive (brownstained) cells and counted the corresponding vessels. The microvessel density was calculated as the average number of microvessels in five fields for each sample. As indicated in Supplementary Figure 14, the microvessel density decreased from $30.2 \pm 1.9$ (control) to $4.0 \pm 1.6$ (I.V., p $<$ $0.01)$ and $1.4 \pm 1.1$ (I.T., $\mathrm{p}<0.01$ ). The tumor proliferation index was further determined by KI67 staining. The positive incidence percentage was $79.8 \pm 2.3 \%$ in the control group, but decreased acutely to $4.6 \pm 1.1 \%$ and $1.6 \pm 1.3 \%$ in mice injected I.T. $(\mathrm{p}<0.01)$ and I.V. $(\mathrm{p}<0.01)$ with $\mathrm{MoS}_{2}-$ PVP nanosheets, respectively. Moreover, we performed a terminal deoxynucleotidyl transferase-mediated dUTPbiotin nick end labeling (TUNEL) assay to analyze the extent of apoptosis in tumors from mice that received different treatments. The average TUNEL-positive cell levels were significantly greater in mice injected I.V. (82.5 $\pm 3.9 \%, \mathrm{p}<0.01)$ and I.T. $(94.2 \pm 1.64 \%, \mathrm{p}<0.01)$ with the nanosheets than in the control group $(1.76 \pm 0.83 \%)$. These immunohistochemical staining results supported the promising in vivo anti-cancer effectiveness of the assynthesized $\mathrm{MoS}_{2}$-PVP nanosheets. Considering the strong in vitro and in vivo dual modal imaging abilities and high biocompatibility of the ultra-small $\mathrm{MoS}_{2}$-PVP nanosheets, we highly expect that they will have diverse applications in biomedicine.

In summary, we have reported a one-pot PVPassisted hydrothermal route for the controlled synthesis of ultra-small $\mathrm{MoS}_{2}$-PVP nanosheets. Due to the chelatingcoordinating effect between the lone-pair electrons of the PVP carbonyl oxygen and the unoccupied $4 \mathrm{~d}$ orbitals of Mo, PVP was synchronously grafted onto the surface of ultrasmall $\mathrm{MoS}_{2}$ nanosheets. PVP acted not only as a modifier to equip the $\mathrm{MoS}_{2}$ nanosheets with excellent colloidal stability, but also as a template to guide the growth of the nanosheets. The as-prepared $\mathrm{MoS}_{2}$-PVP nanosheets exhibited strong photothermal conversion efficiency and excellent cyto, hemo- and histocompatibility that may satisfy the strict application requirements for biomedicine. Our findings not only highlight the translational potential of $\mathrm{MoS}_{2}$-based nanomaterials, but also may initiate further exploration into the rational design of nucleus-targeting tumor PTT systems.

\section{MATERIALS AND METHODS}

\section{Materials}

The precursor $\left(\mathrm{NH}_{4}\right)_{2} \mathrm{MoS}_{4}$ was obtained from J\&K Chemical Co., Ltd. (Shanghai, China). PVP (molecular weights [Mws]: $30 \mathrm{kDa}$ and $360 \mathrm{kDa}$ ) and monoethanolamine were purchased from Sinopharm Chemical Reagent Co., Ltd. (Shanghai, China). Human colon cells (HT29) and a mouse fibroblast cell line (L929) were purchased from the Institute of Biochemistry and Cell Biology (Chinese Academy of Sciences, Shanghai, China). Roswell Park Memorial Institute 1640 (RPMI 1640) medium, Dulbecco's Modified Eagle's Medium (DMEM), fetal bovine serum (FBS), penicillin-streptomycin and trypan blue were bought from Gibco (Shanghai, China). Balb/c nude mice with body weights of $\sim 20 \mathrm{~g}$ and four-week-old Kunming (KM) mice were purchased from Shanghai Laboratory Animal Center (Shanghai, China). All animal experiments were carried out according to the guidelines of Changhai Hospital, Second Military Medical University and the policies of the National Ministry of Health. All chemicals were used as received. The water (with resistivity higher than $18.2 \mathrm{M} \Omega \cdot \mathrm{cm}$ ) was treated in a Pall Cascada laboratory water system.

\section{Material preparation}

Pristine $\mathrm{MoS}_{2}$ nanosheets were synthesized by a previously reported method [17]: $300 \mathrm{mg}\left(\mathrm{NH}_{4}\right)_{2} \mathrm{MoS}_{4}$ was dissolved in $60 \mathrm{~mL}$ distilled water and magnetically stirred. The resultant homogenous solution was then 
placed in a $100-\mathrm{mL}$ polyphenylene-lined stainless-steel autoclave and heated at $220{ }^{\circ} \mathrm{C}$ for $12 \mathrm{~h}$. The one-pot hydrothermal synthesis of $\mathrm{MoS}_{2}-\mathrm{PVP}$ was performed as follows: $150 \mathrm{mg}\left(\mathrm{NH}_{4}\right)_{2} \mathrm{MoS}_{4}$ and $150 \mathrm{mg}$ PVP (Mw: 30 or $360 \mathrm{kDa}$ ) were dissolved in $30 \mathrm{~mL}$ water by vigorous magnetic stirring. The resultant homogenous solutions were then pipetted into $100-\mathrm{mL}$ polyphenylene-lined stainless-steel autoclaves and maintained at $220{ }^{\circ} \mathrm{C}$ for $12 \mathrm{~h}$. The final products were washed once with a monoethanolamine solution $(50 \%$ in water, $\mathrm{v} / \mathrm{v})$ and three times with distilled water, and were stored at $4{ }^{\circ} \mathrm{C}$ for later use. The products were denoted as $\mathrm{MoS}_{2}-\mathrm{PVP}_{30 \mathrm{kDa}}$ and $\mathrm{MoS}_{2}-\mathrm{PVP}$ when the Mws of PVP were $30 \mathrm{kDa}$ and 360 $\mathrm{kDa}$, respectively.

\section{Characterization}

Transmission electron microscopy (TEM) was used to observe the microtopography of $\mathrm{MoS}_{2}$ and $\mathrm{MoS}_{2}-\mathrm{PVP}$ nanosheets. The observation was performed with a JEOL$2100 \mathrm{~F}$ analytical electron microscope under an operation voltage of $200 \mathrm{kV}$. To determine the size and thickness of the nanosheets, we randomly measured 50 sheets of each sample from the TEM image in Image J $1.40 \mathrm{G}$ software (http://rsb.info.nih.gov/ij/down-load.html) [24]. The elemental composition of the $\mathrm{MoS}_{2}-\mathrm{PVP}$ nanosheets was analyzed with the X-ray energy dispersive spectroscopy (EDS) module of an FEI Magellan 400 field-emission microscope. The nanosheets were sprayed on mica. X-ray photo-electron spectroscopy (XPS, ESCAlab250, Thermal Scientific) was used to determine the chemical nature of the product. A Rigaku D/max-2200 PC X-ray Diffraction (XRD) system was used to study the crystalline structure of the synthesized nanosheets. The scanning parameters were a $2 \theta$ value of $3^{\circ}$ to $70^{\circ}$ and $\mathrm{Cu} \mathrm{K} \alpha$ radiation with a wavelength of $1.54 \AA$ operated at $40 \mathrm{kV}$ and $40 \mathrm{~mA}$. The surface compositions of the $\mathrm{MoS}_{2}$ and $\mathrm{MoS}_{2}$-PVP nanosheets were evaluated via Fourier transform infrared spectroscopy with a Nicolet 7000-C spectrometer under transmission mode. The scanning was performed within the wavelength range of 400 to $4000 \mathrm{~cm}^{-1}$. The UV-VisNIR light absorption features of the $\mathrm{MoS}_{2}$ and $\mathrm{MoS}_{2}-\mathrm{PVP}$ nanosheets were compared on a UV-3600 Shimadzu UVVis-NIR spectrometer. A NanoBrook 90Plus Particle Size Analyzer system (Brookhaven) equipped with a standard $633-\mathrm{nm}$ laser was used to measure the dynamic light scattering (DLS) size of the $\mathrm{MoS}_{2}$-PVP nanosheets in different media and their Zeta potential in distilled water.

\section{Cell culture and animal model}

L929 and HT29 cells were cultured in 100-mm cell petri dishes (Corning Incorporated) that were filled with 5 mL DMEM or RPMI 1640 medium containing 10\% FBS, 100 units $/ \mathrm{mL}$ penicillin and $100 \mu \mathrm{g} / \mathrm{mL}$ streptomycin. The cells were continuously incubated in a humidified incubator $\left(5 \% \mathrm{CO}_{2}, 37^{\circ} \mathrm{C}\right)$ and the medium was changed every two to three days. The tumor model was established through the subcutaneous injection of $150 \mu \mathrm{L}$ serum-free RPMI 1640 medium containing $1 \times 10^{6}$ HT29 cells into the backs of Balb/c nude mice. Animal experiments were carried out when the tumor volume reached about $\sim 0.5 \mathrm{~cm}^{3}$.

\section{Photothermal conversion performance}

The NIR laser (wavelength $=808 \mathrm{~nm}$ ) used in this research originated from a high-power multimode pump laser (Shanghai Connet Fiber Optics Company). The temperature and thermal images were recorded with a FLIR $^{\mathrm{TM}}$ A320 camera (FLIR, USA). The temperature of an individual hole of a 96-well cell culture plate was recorded to evaluate the NIR photothermal transformation efficiency of the as-prepared $\mathrm{MoS}_{2}-\mathrm{PVP}$ nanosheets. This plate was filled with $100-\mu \mathrm{L} \mathrm{MoS}_{2}-\mathrm{PVP}$ nanosheet aqueous dispersions at different concentrations and continuously irradiated by the NIR laser. Distilled water was set as the control. The mass extinction coefficient $(\kappa)$ can be calculated by the Lambert-Beer law: $A=\kappa \cdot C \cdot L$, where $\mathrm{A}$ is the absorbance that can be determined from the UV-Vis-NIR curve, $\mathrm{C}$ is the concentration of the $\mathrm{MoS}_{2}-$ PVP nanosheets (unit: $\mathrm{mg} / \mathrm{mL}$ ) and $\mathrm{L}$ is the optical length $(\mathrm{L}=1 \mathrm{~cm})$ of the quartz microplate.

\section{Cellular uptake of $\mathrm{MoS}_{2}$ nanosheets}

The cellular uptake of the $\mathrm{MoS}_{2}$-PVP nanosheets was studied through inductively coupled plasma optical emission spectroscopy (ICP-OES) and Bio-TEM. Briefly, HT2 9 cells at a density of $5 \times 10^{5}$ cells/well were seeded in a six-well tissue culture plate and incubated overnight to allow the thorough adherence and spreading of cells. Then, the wells were replenished with RPMI 1640 medium containing $\mathrm{MoS}_{2}$-PVP nanosheets $(200 \mu \mathrm{g} / \mathrm{mL})$ and the cells were cultured for an additional $6 \mathrm{~h}$. Subsequently, the cell culture medium was discarded and the cells were rinsed with phosphate-buffered saline three times. These cells were finally dissolved in $1 \mathrm{~mL}$ aqua regia solution for ICP-OES analysis to quantify the Mo content internalized by the cells.

Bio-TEM was performed to further assess the cellular uptake of the $\mathrm{MoS}_{2}-\mathrm{PVP}$ nanosheets. Approximately $8 \times 10^{6}$ HT29 cells were seeded in a 100 $\mathrm{mm}$ cell culture dish and incubated overnight to allow cellular adherence and spreading. Then, the wells were replenished with RPMI 1640 medium containing $\mathrm{MoS}_{2}-$ PVP nanosheets $(1 \mathrm{mg} / \mathrm{mL})$ and the cells were cultured for an additional $6 \mathrm{~h}$. After the cell culture medium was discarded and the dish was washed with phosphatebuffered saline three times, the cells were trypsinized and fixed with 2.5 wt. $\%$ glutaraldehyde at $4{ }^{\circ} \mathrm{C}$. Cells were visualized with a Hitachi H600 transmission electron microscope at an operating voltage of $60 \mathrm{kV}$. 


\section{In vitro cytocompatibility evaluation and PTT}

A typical Cell Counting Kit-8 (CCK-8) assay was used to study the in vitro cytocompatibility of the $\mathrm{MoS}_{2}-$ PVP nanosheets. In brief, L929 and HT29 cells at a seeding density of $\sim 8 \times 10^{3}$ cells/well were dispersed in $100 \mu \mathrm{L}$ of the corresponding medium and added to individual wells of a 96-well plate. The cells were then incubated with fresh medium containing a pre-determined concentration of $\mathrm{MoS}_{2}$ nanosheets. After $24 \mathrm{~h}$ of incubation, the cellular metabolic activity was determined with the CCK- 8 kit according to the manufacturer's instructions. The cellular morphology was also observed with a Leica DM IL LED inverted-phase contrast microscope to evaluate the viability of the L929 and HT29 cells qualitatively.

For the in vitro PTT, $\sim 8 \times 10^{3}$ HT29 cells dispersed in $100 \mu \mathrm{L}$ RPMI 1640 medium were pipetted into individual wells of a 96-well plate and cultured overnight. Then, pre-determined concentrations of $\mathrm{MoS}_{2}-\mathrm{PVP}$ nanosheets were added and incubated for another $6 \mathrm{~h}$. After that, the cells were irradiated with the NIR laser $\left(0.6 \mathrm{~W} / \mathrm{cm}^{2}\right)$ for $1 \mathrm{~min}$ or $5 \mathrm{~min}$ and incubated for $24 \mathrm{~h}$. A CCK-8 kit, Leica DM IL LED inverted-phase contrast microscope and trypan blue staining were used to evaluate the in vitro PTT effect quantitatively and qualitatively.

\section{Hemocompatibility of $\mathrm{MoS}_{2}$ nanosheets}

For in vitro hemocompatibility experiments, KM mice were anesthetized for heart puncturing to collect blood. Mouse red blood cells (mRBCs) were collected following centrifugation and removal of the serum, and the cells were stored in saline at $4{ }^{\circ} \mathrm{C}$. Then, a $0.2-\mathrm{mL} \mathrm{mRBC}$ suspension was treated with $0.8 \mathrm{~mL}$ of a dispersion of $\mathrm{MoS}_{2}-\mathrm{PVP}$ nanosheets $(200 \mu \mathrm{g} / \mathrm{mL})$ and saline in a 1.5 -mL Eppendorf tube at $37^{\circ} \mathrm{C}$ for $2 \mathrm{~h}$. The treated mRBCs were harvested via centrifugation (10000 rpm, $1 \mathrm{~min}$ ) and their morphology was visualized according to the instructions for Wright's stain.

For in vivo serum biochemistry and routine blood testing, 200- $\mu \mathrm{L} \mathrm{MoS}_{2}-\mathrm{PVP}$ nanosheet dispersions (1 $\mathrm{mg} / \mathrm{mL}$ ) were intravenously (I.V.) administered to KM mice. On day $1,7,14$, or 28 after the material injection, mice were anesthetized for heart puncturing to collect blood. The harvested blood was centrifuged to separate the blood serum for biochemical parameter analysis and a coagulation assay. An ACL 200 blood coagulation analyzer was used to assess typical coagulation parameters, including the prothrombin time (PT), activated partial thromboplastin time (APTT) and fibrinogen level (FIB), according to the instructions of a HemosIL ${ }^{\mathrm{TM}}$ kit. For routine in vivo blood testing, the harvested blood was stabilized by heparin. A Sysmex XS800i automated hematology analyzer was used to record various parameters, including the levels of white blood cells (WBC), hemoglobin (Hb), platelets (PLT), red blood cells $(\mathrm{RBC})$ and hematocrit (HCT), the mean corpuscular volume (MCV), the mean corpuscular hemoglobin $(\mathrm{MCH})$, the mean corpuscular hemoglobin concentration (MCHC) and the red cell distribution width (RDW).

\section{In vivo biodistribution and histology examinations}

After the hemocompatibility assay, KM mice were euthanized and their major organs (heart, liver, spleen, lung and kidney) were weighed and cut into two equal parts. The first part of each organ was dissolved in an aqua regia solution to quantify the amount of Mo with an Agilent 700 Series ICP-OES. The remaining part of each organ was fixed with formaldehyde and used for hematoxylin and eosin (H\&E) staining to diagnose pathological changes, according to standard procedures for $\mathrm{H} \& \mathrm{E}$ staining. Healthy mice without material injection were used as controls.

\section{In vitro and in vivo photoacoustic imaging}

In vitro photoacoustic imaging was performed with a Vevo LAZR Photoacoustic Imaging System at a wavelength of $808 \mathrm{~nm}$. Before the test, aqueous $\mathrm{MoS}_{2}-$ PVP nanosheet dispersions $(15 \mu \mathrm{L})$ at concentrations of 25,50 and $100 \mathrm{ppm}$ were transferred into small holes in a home-made agar plate. For the in vivo photoacoustic imaging, two tumor-bearing Balb/c nude mice (tumor volume: $\left.\sim 0.5 \mathrm{~cm}^{3}\right)$ were anesthetized and injected with either $100 \mu \mathrm{L}$ (I.V.) or $30 \mu \mathrm{L}$ (intratumorally [I.T.]) of a $\mathrm{MoS}_{2}-\mathrm{PVP}$ nanosheet dispersion. Mice with I.V. saline injection were set as controls. Mice were euthanized 12 $\mathrm{h}$ or immediately after the I.V. or I.T. injection, and the tumors were harvested in $1.5-\mathrm{mL}$ Eppendorf tubes and fixed with formaldehyde for photoacoustic imaging (Vevo LAZR Photoacoustic Imaging System).

\section{In vivo PTT}

Tumor-bearing Balb/c mice were randomly divided into three groups ( $\mathrm{n}=6$ per group) and injected with 100 $\mu \mathrm{L}$ saline (I.V., control, group 1), $100 \mu \mathrm{L}$ of the $\mathrm{MoS}_{2}-\mathrm{PVP}$ nanosheet dispersion (I.V., group 2) or $30 \mu \mathrm{L}$ of the $\mathrm{MoS}_{2}-$ PVP nanosheet dispersion (I.T., group 3). Mice in groups 1 and 3 were treated with NIR irradiation $\left(0.6 \mathrm{~W} / \mathrm{cm}^{2}, 5 \mathrm{~min}\right)$ immediately after the injection. Mice that received I.V. material injection were treated with NIR irradiation (0.6 $\mathrm{W} / \mathrm{cm}^{2}, 5 \mathrm{~min}$, group 2) $12 \mathrm{~h}$ after the material injection to allow time for the $\mathrm{MoS}_{2}-\mathrm{PVP}$ nanosheets to travel through the blood vessels and reticuloendothelial system organs and reach the tumor. The temperature and thermal images were recorded with a FLIR ${ }^{\mathrm{TM}}$ A320 camera (FLIR, USA). The in vivo PTT performance was determined based on immunohistochemical analysis, the relative tumor volume $\left(\mathrm{V} / \mathrm{V}_{0}\right.$, where $\mathrm{V}_{0}$ represents the initial subcutaneous tumor volume at day 0 ) and the tumor appearance. 


\section{Statistical analysis}

One-way analysis of variance was performed to evaluate the significance of the experimental data. A significance level of 0.05 was selected, and the data were marked with (*) for a probability value less than 0.05 (p $\left.<0.05),{ }^{* *}\right)$ for $\mathrm{p}<0.01$, and $\left({ }^{* * *}\right)$ for $\mathrm{p}<0.001$. Unless specified, the sample size was three $(\mathrm{n}=3)$.

\section{CONFLICTS OF INTEREST}

The authors declare that they have no conflicts of interest.

\section{FUNDING}

This work was supported by the National Natural Science Foundation of China (Grant No. 81370493).

\section{REFERENCES}

1. Wang S, Hu F, Li J, Zhang S, Shen M, Huang M, Shi X. Design of electrospun nanofibrous mats for osteogenic differentiation of mesenchymal stem cells. Nanomedicine. 2017. https://doi.org/10.1016/j.nano.2016.12.024.

2. Novoselov KS, Geim AK, Morozov SV, Jiang D, Zhang Y, Dubonos SV, Grigorieva IV, Firsov AA. Electric field effect in atomically thin carbon films. Science. 2004; 306: 666-9.

3. Lin Y, Connell JW. Advances in 2D boron nitride nanostructures: nanosheets, nanoribbons, nanomeshes, and hybrids with graphene. Nanoscale. 2012; 4: 6908-39.

4. Kurapati R, Kostarelos K, Prato M, Bianco A. Biomedical uses for 2D materials beyond graphene: current advances and challenges ahead. Adv Mater. 2016; 28: 6052-74. https://doi.org/10.1002/adma.201506306.

5. Yang K, Li YJ, Tan XF, Peng R, Liu Z. Behavior and toxicity of graphene and its functionalized derivatives in biological systems. Small. 2013; 9: 1492-503. https://doi. org/10.1002/smll.201201417.

6. Coleman JN, Lotya M, O’Neill A, Bergin SD, King PJ, Khan U, Young K, Gaucher A, De S, Smith RJ. Twodimensional nanosheets produced by liquid exfoliation of layered materials. Science. 2011; 331: 568-71.

7. Shen J, Song G, An M, Li X, Wu N, Ruan K, Hu J, Hu $\mathrm{R}$. The use of hollow mesoporous silica nanospheres to encapsulate bortezomib and improve efficacy for non-small cell lung cancer therapy. Biomaterials. 2014; 35: 316-26. https://doi.org/10.1016/j.biomaterials.2013.09.098.

8. Wang S, Zhao J, Yang H, Wu C, Hu F, Chang H, Li G, Ma D, Zou D, Huang M. Bottom-up synthesis of WS2 nanosheets with synchronous surface modification for imaging guided tumor regression. Acta Biomaterialia. 2017; 58: 442-54. https://doi.org/10.1016/j.actbio.2017.06.014.
9. Fuhrer MS, Hone J. Measurement of mobility in dual-gated $\mathrm{MoS}_{2}$ transistors. Nat Nanotechnol. 2011; 8: 146-7.

10. He Q, Zeng Z, Yin Z, Li H, Wu S, Huang X, Zhang H. Fabrication of flexible $\mathrm{MoS}_{2}$ thin film transistor arrays for practical aas sensing applications. Small. 2012; 8: 2994-9.

11. Tian Q, Jiang F, Zou R, Liu Q, Chen Z, Zhu M, Yang S, Wang J, Wang J, Hu J. Hydrophilic $\mathrm{Cu}_{9} \mathrm{~S}_{5}$ nanocrystals: a photothermal agent with a $25.7 \%$ heat conversion efficiency for photothermal ablation of cancer cells in vivo. ACS Nano. 2011; 5: 9761-71.

12. Chen D, Chen W, Ma L, Ji G, Chang K, Lee JY. Graphenelike layered metal dichalcogenide/graphene composites: synthesis and applications in energy storage and conversion. Mater Today. 2014; 17: 184-93.

13. Chou SS, Kaehr B, Kim J, Foley BM, De M, Hopkins PE, Huang J, Brinker CJ, Dravid VP. Chemically EXFOLIATEd $\mathrm{MoS}_{2}$ as near-infrared photothermal agents. Angew Chem. 2013; 125: 4254-8.

14. Kumar N, George BP, Abrahamse H, Parashar V, Ngila JC. Sustainable one-step synthesis of hierarchical microspheres of PEGylated $\mathrm{MoS}_{2}$ nanosheets and $\mathrm{MoO} 3$ nanorods: their cytotoxicity towards lung and breast cancer cells. Appl Surf Sci. 2017; 396: 8-18. http://doi.org/10.1016/j. apsusc.2016.11.027.

15. Liu T, Chao Y, Gao M, Liang C, Chen Q, Song G, Cheng L, Liu Z. Ultra-small $\mathrm{MoS}_{2}$ nanodots with rapid body clearance for photothermal cancer therapy. Nano Res. 2016; 9: 3003-17.

16. Liu T, Wang C, Cui W, Gong H, Liang C, Shi XZ, Li ZW, Sun BQ, Liu Z. Combined photothermal and photodynamic therapy delivered by PEGylated MoS2 nanosheets. Nanoscale. 2014; 6: 11219-25. https://doi.org/10.1039/ c4nr03753g.

17. Wang S, Li K, Chen Y, Chen H, Ma M, Feng J, Zhao Q, Shi J. Biocompatible PEGylated $\mathrm{MoS}_{2}$ nanosheets: controllable bottom-up synthesis and highly efficient photothermal regression of tumor. Biomaterials. 2015; 39: 206-17.

18. Wang Z, Li H, Liu Z, Shi Z, Lu J, Suenaga K, Joung SK, Okazaki T, Gu Z, Zhou J. Mixed low-dimensional nanomaterial: 2D ultranarrow MoS2 inorganic nanoribbons encapsulated in quasi-1D carbon nanotubes. J Am Chem Soc. 2016; 132: 13840.

19. Feng W, Chen L, Qin M, Zhou XJ, Zhang QQ, Miao YK, Qiu KX, Zhang YZ, He CL. Flower-like PEGylated MoS2 nanoflakes for near-infrared photothermal cancer therapy. Sci Rep. 2015; 5: 17422. https://doi.org/10.1038/srep17422.

20. Novoselov K, Jiang D, Schedin F, Booth T, Khotkevich V, Morozov S, Geim A. Two-dimensional atomic crystals. Proc Natl Aacd Sci U S A. 2005; 102: 10451-3.

21. Zeng Z, Yin Z, Huang X, Li H, He Q, Lu G, Boey F, Zhang H. Single-layer semiconducting nanosheets: High-yield preparation and device fabrication. Angew Chem-Int Edit. 2011; 50: 11093-7. 
22. Yin W, Yan L, Yu J, Tian G, Zhou L, Zheng X, Zhang X, Yong Y, Li J, Gu Z. High-throughput synthesis of singlelayer $\mathrm{MoS}_{2}$ nanosheets as a near-infrared photothermaltriggered drug delivery for effective cancer therapy. ACS Nano. 2014; 8: 6922-33.

23. Osim W, Stojanovic A, Akbarzadeh J, Peterlik H, Binder WH. Surface modification of $\mathrm{MoS}_{2}$ nanoparticles with ionic liquid-ligands: towards highly dispersed nanoparticles. Chem Commun. 2013; 49: 9311-3.

24. Lu X, Au L, McLellan J, Li ZY, Marquez M, Xia Y. Fabrication of cubic nanocages and nanoframes by dealloying $\mathrm{Au} / \mathrm{Ag}$ alloy nanoboxes with an aqueous etchant based on Fe (NO3) 3 or NH4OH. Nano Lett. 2007; 7: 1764-9.

25. Chithrani BD, Ghazani AA, Chan WC. Determining the size and shape dependence of gold nanoparticle uptake into mammalian cells. Nano Lett. 2006; 6: 662-8.

26. Wang S, Zhao J, Hu F, Li X, An X, Zhou S, Chen Y, Huang M. Phase-changeable and bubble-releasing implants for highly efficient HIFU-responsive tumor surgery and chemotherapy. J Mater Chem B. 2016; 4: 7368-78 .
27. Balasubramanian SK, Jittiwat J, Manikandan J, Ong CN, Yu LE, Ong WY. Biodistribution of gold nanoparticles and gene expression changes in the liver and spleen after intravenous administration in rats. Biomaterials. 2012; 31 : 2034-42.

28. Lin H, Wang X, Yu L, Chen Y, Shi J. Two-dimensional ultrathin mxene ceramic nanosheets for photothermal conversion. Nano Lett. 2017; 17: 384-91.

29. Cai X, Gao W, Ma M, Wu M, Zhang L, Zheng Y, Chen H, Shi J. A prussian blue-based core-shell hollow-structured mesoporous nanoparticle as a smart theranostic agent with ultrahigh pH-responsive longitudinal relaxivity. Adv Mater. 2015; 27: 6382-9. https://doi.org/10.1002/adma.201503381.

30. Cai X, Gao W, Zhang L, Ma M, Liu T, Du W, Zheng Y, Chen H, Shi J. Enabling prussian blue with tunable localized surface plasmon resonances: Simultaneously enhanced dual-mode imaging and tumor photothermal therapy. ACS Nano. 2016; 10: 11115-26. https://doi. org/10.1021/acsnano.6b05990. 